\title{
CJEM Debate Series: what's in a name? It is simply an emergency room, and we are ERPs!
}

\author{
Andrew MacPherson ${ }^{1,2} \cdot$ David A. Petrie $^{3} \cdot$ John M. Tallon ${ }^{1} \cdot$ Bruce Campana $^{1,2} \cdot$ Paul Atkinson $^{4}(\mathbb{D}$ \\ Received: 25 March 2021 / Accepted: 1 April 2021 / Published online: 10 May 2021 \\ (C) The Author(s), under exclusive licence to Canadian Association of Emergency Physicians (CAEP)/ Association Canadienne de Médecine d'Urgence \\ (ACMU) 2021
}

Keywords Emergency Department $\cdot$ Emergency Physician $\cdot$ Professional identity formation $\cdot$ Health system redesign

\section{Introduction: Paul Atkinson (@ PaulAtkinsonEM)}

This series of editorials provides CJEM readers with the opportunity to hear differing perspectives on topics pertinent to the practice of Emergency Medicine. The debaters have been allocated opposing arguments on topics where there is some controversy or perhaps scientific equipoise.

We continue with the topic of what we in emergency medicine prefer to be called, and what we call our place of work-our identity! Does it matter? Do we work in a room or a department? Are we defined by what we do, how we are trained, or where we work? Do these descriptions impact how we see ourselves and how others see us and our role in the healthcare system? Or is it better just to do our jobs and let popular opinion and media discourse decide what we should be called? Emerg, Casualty, $A \& E$, the Outdoor, Outpatients, $E R$, and $E D$ are some of the terms used to describe where we work. Some are local, some historical, some stem from television shows that perhaps nudged a few of us into the job! Emergency Medicine is what we do, right? David Petrie and John Tallon feel that names matter, and that perhaps we should be careful how we wish to be thought of-and that 'ERP' is not that! First though, Andrew

David A. Petrie

DavidA.Petrie@nshealth.ca

1 Department of Emergency Medicine, University of British Columbia, Vancouver, BC, Canada

2 Department of Emergency Medicine, Island Health, Victoria, BC, Canada

3 Department of Emergency Medicine, Dalhousie University, Nova Scotia Health, Halifax, NS, Canada

4 Department of Emergency Medicine, Dalhousie University, Horizon Health Network, Saint John, NB, Canada
MacPherson and Bruce Campana provide some west coast chill, and an informal take on the fluidity of names including those for our professional activities and identity. Readers can follow the debate on Twitter and vote for either perspective, by going to @ CJEMonline or by searching \#CJEMdebate.

\section{For: Andrew MacPherson, Bruce Campana [mostly Campana]}

\section{You say EP, I say ERP_let's call the whole thing off}

We are not Emergency Department Physicians. EDPs? Anybody who tells you otherwise is wrong. We meet our patients where they are, at the place they are in (core content, Can Meds, ${ }^{1}$ see 2.1 and CFPC $^{2}$ ). In our case, this happens to be a room. Any sane ${ }^{3}$ CAEP member will tell you that we do not have control over the department. If we did, then we would not house any admitted patients. ${ }^{4}$

We all must agree that we see and help people in rooms. Even if we see them in the waiting room, it is the waiting ROOM. Or the trauma ROOM. If we see them in the hallway, well, perhaps that is not a room, but should we really be picking our title because we see patients in hallways? Emergency Hallway Physicians? EHPs?

\footnotetext{
1 https://www.royalcollege.ca/rcsite/canmeds/framework/canmedsrole-medical-expert-e.

2 https://portal.cfpc.ca/resourcesdocs/uploadedFiles/Education/The\% 20Patient-Centred\%20Approach.pdf.

3 There have to be some.

${ }^{4}$ https://www.healthaffairs.org/doi/abs/10.1377/hlthaff.2011.0786? journalCode $=$ hlthaff.

5 Don't be silly.
} 
Others may argue that we need a whole department to help and heal the sick. We could argue that we need more than that. Not because we are needy, ${ }^{6}$ but because we rely on a whole cadre of teams: diagnostic imaging (or whatever it is called now), laboratory (or whatever it is called now), social work (called social work usually, we think), and all of the rest of the components of our medical system. We guide our patients through the system. But we are not emergency 'medical system' physicians, we are emergency physicians, who meet patients where they are-in a room. ${ }^{7}$ So, we are Emergency Room Physicians. Also known as ERP. Say it out loud. So good.

Identity fluidity is commonplace now, why not name fluidity? That's not a new concept. John Wayne, who was not a good example of anything good, was actually Marion Morrison. Prince was... whatever he was before Prince, which he was until he was something else. The point is, we can be called whatever we want, when we want. Identity is important.

Clerk: "Can we have the EP to the red phone please?".

Physician, in chosen voice of the day, Bugs Bunny: "I'm not an EP! Dis week I'm da Tremendous Wasuscitationologist for high Impact Twauma ${ }^{8}$ !".

Clerk: "Fine. Could we have the TWIT to the phone please?". 9

Senior staff could go to work as the "Doctor with Advanced Capabilities in Ostensibly Obtuse Clinically Obscure Nonsensical Emergencies". ${ }^{10}$

EP sounds wrong. Say it out loud. Sounds like a hard of hearing uncle asking you to speak up, or a question of urinary continence.

Names are important. Is the Tasselled wobbegong happy with their name, or would aplacental viviparous bearded shark be preferred? The Colon rectum, a Canadian beetle, may be jealous of the Hercules beetle, Goliath beetle or giant longlegged katydid. Would renaming these animals make them a better beetle [or shark]? While nomenclature is important, new names do not change the fact that you are a floating carpet, or dung eater. Or Emergency Room Physician [ERP] for that matter. Cool names just make you cool, but you still do the same stuff. So let us have a cool name, not a scientific name. Renaming us will not change what we do.

\footnotetext{
${ }^{6}$ We aren't, in general. But Dave Petrie is. He's all clingy, like a koala with an FRCPC. Winning debates requires that you make all parties feel involved.

${ }^{7}$ I think we have already won.

${ }^{8} \mathrm{Bad}$ example. Not everybody makes good decisions, which is why this debate is important.

9 We have a clerk like this.

${ }^{10}$ DA COOL ONE. We didn't want you to miss this.
}

We also accede that "pHysicians who rEceive AmbuLancEs and walk-in patients with acute pRoblemS" (HEALERS) go by many names. Let us also be clear: most people have alternate names. We independently phoned the partners of everyone ${ }^{11}$ in this debate to get their pet names. John is "PoohBear". ${ }^{12}$ Andrew is "My Big Bad Bald Boy". ${ }^{13}$ Dave is "Snooks". ${ }^{14}$ Bruce's wife calls him "Debbie". ${ }^{15}$

English is a rich language. We have many words that mean the same thing, or are very similar (synonyms). There are very few things that only have one word to describe them. ${ }^{16}$ Go ahead-name a word, and we can come up with one or more synonyms:

Ball: Sphere, orb.

Elephant: Pachyderm.

Redundant: Useless, unnecessary, John Tallon. ${ }^{17}$

You get the idea.

Our fecundity of felicitations ${ }^{18}$ is a blessing. We can pick and choose. A gastroenterologist, besides being depressed, is just a gastroenterologist. We have a choice. We can be an "... ist" (emergentologist). We can be a physician (emergency physician). We can be an officer (casualty officer). We can be onomatopoetic (ERP). ${ }^{19}$ But we cannot be an EDP, because it sounds even weirder than EP, and the name must be cool.

Licensing authorities cannot agree on what to call us. Consultant in Emergency Medicine (UK). Casualty Officer (Edmonton)—no comment. ${ }^{20}$ Emergency Medicine Physician [Australia] — actually, we kind of like that. 'Emergency Physicians' in Germany are usually Anesthesiologists, but in ambulances. ${ }^{21}$ Malaysia credentials physicians with a Master's degree in Emergency Medicine. Switzerland is still trying to define what an Emergency Medicine Physician is. Presumably, they are being neutral about it. ${ }^{22}$

\footnotetext{
${ }^{11}$ No, we didn't.

12 No, he's not.

13 Andrew: We can't call people random names, Bruce. We need substance, not name calling. We argue that we can be called what we want, not what others want! And footnotes are old school, man. I mean, who uses them anymore? Please edit before submitting! Bruce: Edit what?

${ }^{14}$ No, he's not.

15 Bruce: Shut up Andrew.

16 We could only come up with two: pi-meson and marshmallow. We think that's it.

${ }^{17}$ https://emergency.med.ubc.ca/about/administrative-staff/ We think Roy could do it on his own, right?

18 Alliteration: not for sissies.

19 Say 'ERP' out loud again. Isn't that awesome?

${ }^{20}$ We promise not to pick on Alberta, only hockey fans. Including Albertan hockey fans.

21 Which are actually ROOMS, on wheels.

${ }^{22}$ Histology joke. If you don't get it, ask an old guy, like Campana or Tallon.
} 
Anyways, our name should match our profession: snazzy, memorable, rumbustious ${ }^{23}$ but with red-carpet velvety smooth enunciation.

We have come so far from the days where 'A\&E' was run by 'house staff'. Canada benefits from expertly trained, insightful, dedicated physicians who thrive on helping and healing patients. Bring us the sick, the scared (less scared, when they are in a ROOM) to a place where we can help. And if we do need somebody to help us-say a gastroenterologist to do one of their 'exciting' gastroenterology things - they do it in a ROOM.

With our abundance of appellations, we can call ourselves what we want, especially if it sounds good. Except, of course, no one would want to be called the Canucks or the Maple Leafs. ${ }^{24}$ With our onomastic omnipotence, ${ }^{25}$ we could even change our own names. We could wear digital name tags tied to our mood of the week or day, or to our personal wellness, like a cosmically linked Blue-toothed ${ }^{\circledR}$ mood ring. Although frequent changes might make it difficult:

Clerk overhead page: "Could I have Dr. Happy... err... sorry... Dr. Grumpy and Gassy to the phone please?".

We should celebrate our polynomial ${ }^{26}$ nature. We do more stuff than anyone, so we get more names than anyone. The TV show $E R$ was a hit because we do so much, and the title was cool. Imagine if you were an endocrinologist? Their title: Endocrinologist. Nothing else. And, endocrinologist's kids cannot even tell their friends what their parents do until about grade 11. Also, no one makes TV shows about endocrinologists:

“This week, Jessica struggles with Jason's glucose of

11 , agonizing about adding 2 or 3 units of insulin to... zzzz."

We digress.

So let us get with it, Emergency Colleagues. Names are fluid. Gender is fluid. This article is fluid. Countries are fluid. We deal in a variety of fluids. We meet patients where they are (fluidly, smoothly, professionally) in a room. ${ }^{27}$ Shun onomatophobia. ${ }^{28}$ Embrace our plethora of pseudonyms, our multiplicity of monikers, our excess of epithets, our deluge of delegations, and be happy that you are not a depressed, naked, gastroendocrinologist. Or worse-a Canuck or Maple Leaf-because they get called a lot of names. ${ }^{29}$

\footnotetext{
${ }^{23}$ Def'n: "Full of rumbustiousness." You're welcome.

${ }^{24}$ Because they aren't very good. Do we have to explain everything?

25 You'll never see that in NEJM. CJEM is the best.

26 May not be a word.

27 See what we did there?

28 But fear kangaroos. That's macropodophobia. Look it up.

29 Because they aren't very good.
}

Most importantly: our colleagues are wrong. EDP? EP? "Thbbftt". ${ }^{30}$ We respect ${ }^{31}$ that they can call themselves whatever they want, even if they are distressingly, depressingly, distastefully, diabolically wrong. But it must sound good. We are Emergency Medicine Physicians ${ }^{32}$ who see people in ROOMS. Hey! The words Medicine and Physician are essentially synonyms! ${ }^{33}$ So Emergency Physicians, then, working in a room. We are Emergency Room Physicians. Or ERPs. ${ }^{34}$ Be proud.

\section{Against: Dave Petrie and John Tallon (@ jonmurraytallon)}

\section{ERPs, Burps, and other forms of Eructation}

\author{
"Charge ERP, Charge ERP to Resus ONE!"-Over- \\ head page, Metro General Hospital, Canada \\ "What is this ERP?"- -visiting senior resident in EM \\ during transition to practice phase of CBE
}

ERP is a common, guttural eruption from the mouths of some health care professionals in Canadian Emergency Departments (EDs) and is becoming an informal identity marker as Emergency Medicine (EM) matures in the twentyfirst century. ERP supersedes the dismissive "itinerant doc", and the old pejorative "casualty officer", still used in some faraway Emergency Departments, to summon the image of a warm and licensed physician body to lead resuscitative patient care and/or the diagnosis [1] and treatment in unexpected/undifferentiated illness and injury in our communities. In some EDs in Canada, it has moved from 1990's slang to actually appear on various pre-printed orders or even on annual privileging documents. Emergency Medicine is practiced across Canada, but the utterance of the anachronous acronym "ERP" can still be heard in many of them.

"ER", the related acronym, is a term that comes from the last century and was just that-a room in outpatients where the sicker patients went. It caught on in the 1990s in North America with the rise of the TV show by the same name. One of the problems with that vernacular is that it carries with it several assumptions and biases but no standards regarding staffing, equipment, or access to support services like laboratory and diagnostic imaging. Ironically, during the 1980s Emergency Medicine was recognized in Canada

\footnotetext{
$\overline{30}$ Bill the Cat. Always reference your important quotes.

31 No we don't.

32 An EMP is an electronic mega-event thing that destroys stuff, so we can't be that.

33 See, and now you know what synonym means. Well done you!

${ }^{34}$ Say it out loud. Ha. Never gets old. Like Bruce.
} 
as a specialty by the Royal College (and eventually Pediatric Emergency Medicine as a sub-specialty), and by the College of Family Physicians of Canada as an area of added competency. By the 90's Colleges, national associations, and certifying bodies around the world had clarified standards and defined minimum specifications of what it is to be an Emergency Department, and defined expectations of training and certification for emergency physicians. Of note, there is no professional designation in medicine anywhere (not from the College of Family Physicians Canada, the Royal College, nor from the CMA or CMPA) known as ERP.

\section{A rose by any other name?}

Without clarity skills, we cannot advocate for ourselves, our families, our communities, or our values" [2]-Theo Dawson.

In Canada, there is confusion around the use of many terms and acronyms in the domain of emergency care; ER (and ERP), ED (and EP), CEC-Community Emergency Centres in Nova Scotia and even "out-patients"-which is sometimes used synonymously with Emergency Department. Then there is the UPCC (Urgent and Primary Care Centres in BC), the UTC (Urgent Treatment Centre in the UK) and even the term "urgent care centre" is being used in increasingly ambiguous ways to conflate categories with retail medicine "walk-in" clinics [3].

The lack of standardization and clarity in language has created a disconnect in advancing important health system priorities for Emergency Medicine and patients. This includes optimizing the number and distribution of EDs in a region, aligning deliverables with pay in physician contracts, horizontal integration issues with EMS system status plans, vertical integration with specialty services, and optimizing the availability times of Laboratory and Diagnostic Imaging, etc. The patient's perspective in assessing their needs and their access to the labyrinthine health system when they are seeking emergency care is also challenging in this milieu. The recondite principles of physician eligibility, support, and maintenance of competence to practice emergency medicine remain thorny, and poorly addressed with the use of terms like ER and ERP $[4,5]$.

The argument that Emergency Department is a better term (than "ER") for us to use (and that the term "ERP" naturally follows the use of ER) goes like this:

1. Logic of language - a room, by definition, is characterized by its walls, and is a definition of space or form. Emergency Department, and more generally, emergency care services are not defined by walls (do not we have enough walls in our world) but by connections and is a definition of function (in relation to the broader system). The ED is increasingly thought of as a node in a broader Integrated Network of Emergency Care [6]. Form (and the language that describes it) should follow function in health care system design [7] and they both should evolve over time.

2. National/international precedent-The term recommended by the Canadian Association of Emergency Physicians (CAEP not CAERP) is Emergency Department [8], the term used in position statements around the world is Emergency Department, and the peer-reviewed term in most indexed journals is Emergency Department. The American College of Emergency Physicians (ACEP not ACERP) uses the same ED language [9], as do the other two large English language professional associations; The Royal College of Emergency Medicine from the UK (RCEM) [10] and the Australasian College of Emergency Medicine (ACEM) [11].

3. Second order implications - as an example of how lazy language creates flawed mental models which leads to poor policy decisions... unfortunately the term ER has led to the "obvious" (but wrong) use of the term "ERP" and the sloppy syllogism that "an ERP is an ERP is an ERP". In an era of competence-based education, Emergency Medicine seems to be the only discipline defined by the location of practice (an "ER") rather than by competencies/education. We do not call a surgeon a DORC (doctor of OR competencies) because they also have skills and competencies which go beyond an OR.

\section{The paradox of identity}

"Who are you... Who, Who... Tell me Who the Hell Are You?-Pete Townsend and John Entwhistle (The Who)

Professional identity formation in medicine has been described as learning to "think, act, and feel like a physician". The concept recognizes the theory that identity can develop in three interdependent domains: personal, relational, and professional [12]. As an individual's various identities mature into an organized whole/self, they must differentiate from their prior identity, not for the purposes of separating completely (bad), but for the purposes of reintegrating into a broader and more mature whole (good). That said, fusion is not the same as integration (fusion is pre differentiation, integration is post-with cells, species, ideas and medical disciplines) [13]. Therein lies the rub, and the potential, for learning to act, think, and feel like an Emergency Physician (as opposed to an ERP - whatever that is?). Taken too far (i.e., too seriously) EM risks becoming just another disconnected and arrogant silo in the house of medicine, but not taking our name and professional identity 
seriously enough mires the discipline of emergency medicine in the fog of fusion (and confusion) and prevents the re-integration of EM into a more robust and resilient health care system [14] (after its necessary and historically important differentiation as a unique body of knowledge and scope of practice which was accomplished in the 1980's as noted).

We suggest reasonable foundational terms (not too serious, but serious enough) to capture the need for clarity and respect in our professional identity development without losing our humility (or sense of humour):

Emergency Medicine, Emergency Department and Emergency Physician.

As a diverse and pluralistic community of practice, it is not inconsistent to support various paths to certification in $\mathrm{EM}$, and to also understand in what contexts that may not be practical or even advisable, and clear language fosters those conversations and the development of common principles. Without that we end up with grossly flawed physician resource plans contributing to ED closures and EP burnout in Canada.

\section{Context is everything}

I ain't lookin' to block you up, dock or rock or lock you up, analyze you, categorize you, finalize, or advertise you/all I really want to doooooo... is baby be friends with you-Bob Dylan

We get it, some of our best friends call themselves an ERP (sad) and use the term ER (more sad and wrong)... and that's fine, among family (like you may call a brother Kiffer at the beach, and Christopher at the office). But our sense is that when Kiffer is used at the office, either we have not fully thought through the degree to which language creates mental models and influences professional identity formation, or have we recognized the impact syllogisms and poor policy decisions have had in contributing to the constraints we face within the system ${ }^{15}$. It may be that we are just too laid back to care (after all, who really cares-what's in a name, an ED by any other name would smell as sickly sweet at 3 am on a Saturday long weekend); but an element of mature professionalism seems absent in this argument, as does the funny (though nihilistic) arguments of our colleagues in the accompanying editorial.

To be clear, this is not a call for sanctimonious word police, but in the context of senior leadership in Emergency Medicine formally responding to other stakeholder organizations in the system (and for that matter, when we create our own internal documents such as policies, forms, or operational communications) then we agree with Socrates over Shakespeare on this one: "The beginning of wisdom is the definition of terms" and the corollary of this in health systems redesign is likely true: the beginning of confusion and system dysfunction starts with the ambiguity of terms.

Funding No funds were used to produce this manuscript.

\section{Declarations}

Conflict of Interest The authors have no competing interests to declare, financial or otherwise.

\section{References}

1. Dhaliwal G, Detsky AS. The evolution of the master diagnostician. JAMA. 2013;310(6):579-80. https://doi.org/10.1001/jama. 2013.7572.

2. Dawson T. Clarity skills unpacked. Medium 2021; https://theodawson.medium.com/clarity-unpacked-a7dd42461440? source= post_page-----a7dd42461440. Accessed 15 Mar 2021.

3. Martsolf GR. Retail Medical Clinics Do Not Reduce Visits to Hospital Emergency Departments for Minor Health Ailments. RAND Corporation 2016.

4. Motluk A. Call for family doctors to have more emergency medicine training sparks debate. CMAJ. 2018;190(28):E864-5. https:// doi.org/10.1503/cmaj.109-5627.

5. https://canadiem.org/defining-a-specialty-what-is-an-emergencyphysician/. Accessed 15 Mar 2021.

6. Martinez R, Carr B. Creating integrated networks of emergency care: from vision to value. Health Aff (Millwood). 2013;32(12):2082-90.

7. Grumbach K. Redesign of the health care delivery system: a Bauhaus, "form follows function" approach. JAMA. 2009;302(21):2363-4. https://doi.org/10.1001/jama.2009.1772.

8. McEwen J, Borreman S, Caudle J, Chan T, Chochinov A, Christenson J, et al. Position statement on emergency medicine definitions from the canadian association ofemergency physicians. Cambridge University Press; 2018.

9. Definition of Emergency Medicine. American College of Emergency Physicians. Revised June 2015.

10. https://www.rcem.ac.uk/RCEM/Quality_Policy/Policy/Manifesto_ 2019/RCEM/Quality-Policy/Policy/Manifesto_2019.aspx?hkey= 513489cc-1f9a-4428-b574-a69c9145c080 Election Manifesto 2019. The Royal College of Emergency Medicine. Accessed 15 Mar 2021.

11. Better outcomes for our patients. Australian College for Emergency Medicine https://acem.org.au/Content-Sources/AdvancingEmergency-Medicine/Better-Outcomes-for-Patients. Accessed 15 Mar 2021.

12. Cruess RL, Cruess SR, Boudreau JD, Snell L, Steinert Y. A schematic representation of the professional identity formation and socialization of medical students and residents: a guide for medical educators. Acad Med. 2015;90(6):718-25. https://doi.org/10. 1097/ACM.0000000000000700.

13. Wilber K. The pre/trans fallacy. J Humanist Psychol. 1982;22(2):5-43. https://doi.org/10.1177/0022167882222002.

14. Ovens H. COVID-19 pandemic exposes the importance of resilience in health system redesign EM cases waiting to be seen blog (emergencymedicinecases.com). Accessed 15 Mar 2021.

15. Campbell SG, Croskerry P, Petrie DA (2017) Cognitive bias in health leaders. Healthc Manage Forum. 2017;30(5):257-61. https://doi.org/10.1177/0840470417716949. 